\title{
CAMINHOS DE UMA PESQUISA VIRTUAL: UM ESTUDO DE LIDERANÇAS E AÇÃO COLETIVA NO FACEBOOK NO DEBATE SOBRE O DIREITO À CIDADE
}

\author{
PATHS OF A VIRTUAL SEARCH: A STUDY OF LEADERSHIP AND COLLECTIVE ACTION \\ ON FACEBOOK IN THE DEBATE ON THE RIGHT TO THE CITY
}

\author{
Davi Barbosa Cavalcanti ${ }^{1}$ \\ Demétrius Rodrigues de Freitas Ferreira ${ }^{2}$
}

\begin{abstract}
Resumo
Como internautas são mobilizados por líderes virtuais para reivindicar o direito à cidade e discutir política? Este artigo analisa o caso do grupo Direitos Urbanos (DU), o qual é responsável por discutir e articular várias mobilizações no Recife (Brasil) através do Facebook. A proposta é fazer uma discussão metodológica de aspectos que podem orientar investigações atuais e futuras acerca da mobilização de pessoas através das redes sociais virtuais. Metodologicamente, combinou-se a Análise de Redes Sociais (ARS) e a Teoria do Discurso para se compreender o processo de mobilização de pessoas. Foram realizadas entrevistas com líderes virtuais, aplicação de questionários e técnicas de netnografia ${ }^{3}$. Os resultados obtidos indicam a (I) tendência a qual os membros do DU têm de se relacionar com pessoas de círculos sociais parecidos e (II) a identificação das principais ações do DU para mobilizar internautas. A temática é relevante por contemplar desafios contemporâneos de mobilizações recentes, como os Ocupas, Junho de 2013 e os movimentos anti e pró-impeachment de 2015 e 2016 no Brasil.
\end{abstract}

Palavras-chave: Redes Sociais Virtuais; Movimentos Sociais; Lideranças; Facebook; Novas Tecnologias de Informação e Comunicação.

\begin{abstract}
How netizens are mobilized by virtual leaders to claim the right to the city and discuss politics? This article analyzes the case of the Direitos Urbanos (DU), group which is responsible for discussing and articulating various mobilizations in Recife by Facebook. The proposal is to make a methodological discussion of aspects that can guide current and future research on the mobilization of people through virtual social networks. Methodologically, the Social Network Analysis (SNA) and the Discourse Theory were combined to understand the process of mobilizing people. Interviews were conducted with virtual leaders, application of questionnaires and netnography techniques. The main results were the (I) tendency that DU members have on relating to people from similar social circles and (II) the identification of the DU's main actions to mobilize internauts. The theme is

1 Doutorando em Ciência Política pela Universidade Federal de Pernambuco (UFPE). E-mail: davi.barboza@hotmail.com

${ }^{2}$ Doutorando em Sociologia pela Universidade Federal de Pernambuco. E-mail: demetriusrff@gmail.com

${ }^{3}$ Netnografia é uma abordagem participante/observacional on-line que segue um conjunto distinto de procedimentos e protocolos. É apropriada para o estudo de comunidades on-line e interações sociais virtuais (KOZINETS, 2010).
\end{abstract}


relevant considering the contemporary challenges of recent mobilizations, such as the Occupies, June 2013 and the movements pro and against impeachment in Brasil, from 2015 and 2016.

Keywords: Virtual Social Networks; Social Movements; Leadership; Facebook; New Information and Communication Technologies.

\section{INTRODUÇÃO}

O estudo das relações sociais dentro do Facebook, Instagram, Youtube, Twitter e Whatsapp é importante devido ao papel de protagonismo que essas ferramentas virtuais atingiram nas últimas décadas, sendo instrumentos importantes na difusão e organização dos principais protestos do século XXI (ALI et al., 2012; CASTELLS, 2013; DONK et al., 2004; SCHERER-WARREN, 2005). Diante do paulatino aumento de pesquisadores interessados na temática, inclusive brasileiros, o principal objetivo deste trabalho é contribuir metodologicamente ao debate contemporâneo da ação coletiva via redes sociais.

Para tal fim, o artigo se propõe a responder a seguinte questão: de que maneira as pessoas são mobilizadas pelos líderes ${ }^{4}$ de um grupo virtual para reivindicar o direito à cidade e para discutir política? Metodologicamente, combinaram-se as técnicas de Análise de Redes Sociais (ARS) e da Teoria do Discurso (TD) de Laclau e Mouffe para analisar o grupo Direitos Urbanos (DU). A combinação dessas técnicas é recomendada pela literatura específica (HOLLSTEIN, 2012; FERREIRA e FONTES, 2014) como um meio capaz de elucidar a complicada relação entre agência/estrutura e questões relativas à constituição e dinâmica de sistemas sociais. Desse modo, a ARS foi aplicada para identificar as relações estabelecidas entre os atores mais centrais do DU no Facebook; enquanto a TD para compreender e analisar essas relações.

Para alcançar o objetivo proposto, este artigo está organizado da seguinte maneira: (1) breve revisão da literatura (para fins de fundamentação teórica e metodológica), (2) planejamento da pesquisa, (3) caminhos de uma pesquisa virtual, (4) coleta e análise de dados e (5) conclusões.

\footnotetext{
${ }^{4} \mathrm{Na}$ Análise de Redes Sociais, líderes são simplesmente os atores mais centrais de um sistema social. Aqui, para operacionalizar o conceito, a expressão líder se refere ao organizador de um movimento político.
}

Revista de Direito da Cidade, vol. 10, no 2. ISSN 2317-7721 pp. 662-689 663 


\section{Breve revisão da literatura: Análise de Redes Sociais}

Mais antiga do que a internet, a rede social é acima de tudo um tema multidisciplinar. Autores de áreas diversas - como sociologia ${ }^{5}$, matemática, antropologia e psicologia social contribuíram para o desenvolvimento dessa ciência, tais como Euler (com a formulação da teoria dos grafos), Moreno (criador da sociometria), Paul Erdős e Alfred Rényi (desenvolvimento das redes aleatórias), Stanley Milgram (estudo dos “seis graus de separação") e Granovetter (estudo dos laços fortes e fracos).

Mas o que seriam essas redes? Uma rede pode ser interpretada como uma maneira de representar padrões de conexão de um grupo social, sendo vista como um conjunto de dois elementos principais, "os atores (pessoas, instituições ou grupos; os "nós" da rede) e as suas conexões (interações ou laços sociais)" (RECUERO, 2009, p. 24).

A ARS considera essas conexões (estrutura da relação entre atores e posicionamento do ator na rede) características importantes para o comportamento, percepção e atitude das unidades individuais e do sistema em seu conjunto. Consequentemente, os atributos dos indivíduos são secundários e as relações entre os atores são o principal, uma vez que estas explicam os processos e comportamentos sociais com base nas conexões sociais, bem como com base na densidade, centralidade etc.

Na ARS, o pesquisador deve ter atenção ao recolher os dados e ao analisá-los ${ }^{6}$. Pois, após obter os elementos necessários para a pesquisa, que podem ser alcançados através de questionários, por exemplo, é fundamental seguir algumas técnicas para ordenar as informações recolhidas, as quais podem ser transformadas em gráficos e índices (SANTOS, 1996).

De modo a simplificar as informações supracitadas, o estudo de caso que será mostrado mais adiante utilizou sociogramas e índices de centralidade de seis moderadores/ex-moderadores do grupo Direitos Urbanos, investigando as redes primárias destes e alguns atributos (características de um ator ou grupo de atores, tais como idade, gênero, ocupação etc.). A análise

\footnotetext{
${ }^{5}$ Segundo Rodríguez (1995), estudos sociológicos que utilizam a ARS se multiplicaram a partir de 1978, sobretudo com a criação do International Network for Social Network Analysis (INSNA) e suas revistas de divulgação.

${ }^{6}$ Descrições metodológicas de estudos de casos que se utilizam da ARS podem ser vistas em A QAP Network Analysis of Intergovernmental Cooperation between Swiss Cantons (Daniel Bochsler) e Social capital and Health (Ichiro Kawachi).
}

Revista de Direito da Cidade, vol. 10, no 2. ISSN 2317-7721 pp. 662-689 664 
deu ênfase a medidas de centralidade porque, tratando-se do estudo de lideranças, tinha interesse em saber a posição estratégica de um ator dentro das redes estudadas - posições estas que, sendo mais centrais, geralmente implicam em maior poder e controle dos fluxos de comunicação, fatores facilitadores para a troca de recursos entre os "nós" (FONTES, 2012).

\section{Teoria do Discurso, dando voz aos protagonistas}

A TD trabalha com a dimensão da linguagem na análise de objetos empíricos numa implicação mais política e ontológica, fazendo distinção entre o discurso e o extra-discursivo. Para fins analíticos, a TD pode ser empregada como uma estrutura narrativa e conceitual para a análise política de movimentos sociais contemporâneos.

A TD, portanto, propõe aos pesquisadores de movimentos sociais uma reflexão política sobre a circulação e articulação de significados, respondendo a algumas das questões deixadas em aberto pela Teoria de Redes. Uma dessas respostas é "a percepção de que a realidade social é constituída de significados, de sentido, e não apenas de padrões" (FERREIRA; FONTES, 2014). Segundo Howard (2005), um dos objetivos centrais da TD é esclarecer os objetos de estudos problematizados, "mediante sua descrição, compreensão e interpretação" (id, p.43).

Nesse sentido, no estudo de caso que começa a ser explorado a seguir, a TD foi utilizada para analisar parte do discurso dos líderes e pessoas mais atuantes do DU no que se refere a duas questões principais, a articulação e a mobilização de internautas.

\section{PLANEJAMENTO DE UMA PESQUISA}

De acordo com Rodríguez (1995), numa investigação de redes os elementos fundamentais são: a) a escolha da unidade amostral (o objeto de estudo, ou seja, os atores da rede ou tipos de relações mais relevantes para a pesquisa), b) as formas de relação (intensidade da união entre atores ou nível de participação nas mesmas ações), c) o conteúdo relacional (relações de poder, instrumental, sentimental etc.) e d) os níveis de análise (redes egocêntricas, díades, tríades etc.). Este artigo seguiu esses passos.

\section{Compreendendo mobilizações contemporâneas a partir do Direitos Urbanos/Recife}

Revista de Direito da Cidade, vol. 10, o 2. ISSN 2317-7721 pp. 662-689 665 
O século XXI trouxe novos ingredientes ao complexo e por vezes enigmático jogo da ação coletiva. As formas de interação entre seres humanos se transformaram com o desenvolvimento das Novas Tecnologias de Informação e Comunicação ${ }^{7}$ (NTIC), o que fez com que o assunto necessitasse de novos estudos empíricos. Embora venha despertando o interesse de estudiosos (BANDA e MUDHAI, 2009; ESCOBAR e OSTERWEIL, 2009; NANSU PARK et al., 2009), o tema ainda é incipiente, sobretudo por conta da "idade" desses novos movimentos e da "novidade" dos meios tecnológicos utilizados na mobilização (Facebook, Whatsapp, Youtube, Twitter etc.), cujas funções e possibilidades ainda estão sendo descobertas pelos internautas.

Diante desta realidade, é importante esclarecer duas escolhas metodológicas da presente pesquisa. A primeira é o motivo de se estudar a atuação de um grupo virtual apenas no Facebook, ante tantas novas redes virtuais. A segunda é explicar por qual razão o DU foi o grupo eleito.

A relevância científica em estudar um grupo no Facebook $^{8}$ ocorre em função do tamanho e alcance dessa rede virtual, que atualmente é a mais usada no Brasil e no mundo. Em novembro de 2016, o Facebook possuía9: 1,8 bilhão de usuários ativos mensais no mundo (acesso à rede ao menos uma vez por mês); 1,19 bilhão de usuários ativos diários no mundo (acesso ao menos uma vez por dia); 111 milhões de usuários ativos mensais no Brasil; e 82 milhões de usuários ativos diários no Brasil. Antes utilizado preponderantemente para a manutenção de contato entre "amigos", no decorrer dos últimos anos as formas de uso do Facebook sofreram transformações, e com o passar do tempo a rede norte-americana passou a ser vista pelos próprios usuários como uma ferramenta de articulação, denúncia e protesto.

Em relação à escolha do DU, o grupo foi selecionado por ter algumas características inerentes aos movimentos em rede contemporâneos. É organizado principalmente pela internet,

\footnotetext{
${ }^{7}$ As NTIC possuem várias definições. Em geral, referem-se a tecnologias que proporcionam comunicação e informação (seja por meio de cabo, fio ou sem fio) no mundo moderno. Aqui, as NTIC são entendidas como o conjunto de recursos tecnológicos que proporcionam, por meio das funções de hardware, software e telecomunicações, o funcionamento de processos de comunicação, negócios, pesquisas etc.

8 Vale lembrar que embora proporcione as mais variadas formas de ciberativismo, o Facebook é uma empresa privada que lucra com inserções publicitárias. Pesquisa (CANAVARRO, 2014) com a rede gerada pela página "Rio na Rua", presente no Facebook, que cobre manifestações populares no Rio de Janeiro, mostrou que as interações dos usuários geram redes dentro de redes. Diferente das mídias tradicionais - como TV e jornal -, o Facebook precisa que os seus usuários produzam conteúdos e redes (sem cobrar pelo serviço), para que a publicidade vendida pela empresa seja direcionada a perfis específicos de usuários.

${ }^{9}$ Dados oficiais divulgados pelo Facebook. Disponíveis em: <http://br.newsroom.fb.com/company-info/>. Acesso em 16.08.2017.
} 
utiliza-se do Facebook como principal ferramenta de comunicação/mobilização e declara-se, institucionalmente, não ter líderes. Portanto, o grupo foi considerado um objeto de estudo pertinente para se verificar algumas das maneiras de organização/atuação dos novos grupos políticos em rede brasileiros - tema de grande valor às ciências sociais.

\section{Conhecendo o DU}

A origem do DU remete ao início de 2012. À época, algumas pessoas se reuniram para discutir o projeto de Lei conhecido como Marília Arraes, que pretendia proibir o consumo de bebida alcoólica nas ruas recifenses e limitava o horário de funcionamento de bares como medida de combate à violência. Outras pessoas, também desse pequeno grupo, faziam parte de um coletivo menor, o Salve o Caiçara, contra a derrubada de um prédio histórico do Recife que daria lugar a um "espigão".

De encontros entre integrantes desses dois grupos se iniciou um debate acerca de uma grande obra a ser erguida numa área histórica da cidade: o Projeto Novo Recife (PNR), mega complexo empresarial, comercial, hoteleiro e residencial numa área de $100 \mathrm{mil} \mathrm{m}^{2}$. O PNR - hoje modificado após pressões populares, porém igualmente criticado - prevê a construção de ao menos 12 torres, algumas com mais de 40 andares, no Cais José Estelita.

Em janeiro de 2012, cinco ou seis pessoas, conforme relataram os entrevistados desta pesquisa, foram as responsáveis por articular, junto ao Ministério Público e a um vereador, uma audiência pública para discutir o PNR.

Nessa audiência é que a gente anunciou que o DU tinha sido criado, porque a gente percebeu que os grupos anteriores, o de Marília Arraes e o Caiçara, estavam funcionando como receptores de um conjunto de demandas que tinha desrespeito à cidade como um todo, e não só aos temas específicos desses grupos. Então a gente já vinha debatendo a necessidade de se criar um grupo, uma plataforma, um ambiente que permitisse discutir a cidade toda, e aí nessa audiência [...] a gente já foi apresentado como o DU (fala de Apau, uma das fundadoras do DU).

Pouco tempo depois de criado, o DU começou a articular o \#OcupeEstelita na internet, com uma série de atividades para divulgar a importância cultural/histórica do Cais José Estelita. A mobilização chamou a atenção dos principais jornais da cidade e a importância de se discutir o PNR, a ser realizado por um consórcio de gigantes do setor imobiliário composto por Moura Dubeux, Queiroz Galvão, GL Empreendimento e Ara Empreendimentos. Essas empresas adquiriram o 
terreno para a obra da União em 2008, através de um leilão que a Polícia Federal diz ter sido fraudulento, sendo supostamente subfaturada em $\mathrm{R} \$ 10$ milhões $^{10}$.

Com o Ocupe Estelita, o DU ganhou corpo e força, até chegar aos dias atuais, nos quais boa parte das discussões políticas sobre os rumos da Região Metropolitana do Recife passa pela sua página no Facebook, que conta com mais de 31,5 mil participantes. Além do grupo de discussão no Facebook, o DU possui blog, comunidade no Facebook e contas no Youtube e Flickr.

Entre 2012 e 2014, o DU realizou ao menos 15 eventos no Recife, sendo oito relacionados ao PNR (BATISTA, 2015). Além dos já abordados Ocupe Estelita e Salve o Caiçara, outros foram o Ocupe Prefeitura (contra a tentativa de o Conselho de Desenvolvimento Urbano do Recife aprovar o PNR), o Ocupe Agamenon (contra a construção de quatro viadutos sobre a Avenida Agamenon Magalhães, a mais movimentada do Recife) e o Ocupe São Luís (ato cultural que exibiu filmes sobre o crescimento desordenado em grandes cidades). Além disso, o DU colaborou de maneira indireta para a divulgação de vários protestos, sendo um espaço virtual de divulgação de vídeos, textos e imagens.

\section{CAMINHOS DE UMA PESQUISA VIRTUAL}

Diante da variedade de ferramentas e softwares disponíveis para pesquisas virtuais, a partir de agora exploraremos um dos caminhos possíveis, que passou pela aplicação de questionários, entrevistas com líderes virtuais e técnicas de netnografia.

\section{Levantamento de dados}

Realizado em dois momentos, no primeiro observou-se durante 30 dias (de 15 de julho a 13 de agosto de 2015), através de uma ficha pré-codificada (ver Anexo B), a dinâmica da página do grupo do DU no Facebook ${ }^{11}$. Durante esse período, foram separadas as cinco postagens, por dia, com maior número de curtidas. Depois se esmiuçou cada uma, verificando pontos como: (I) assunto

10 Disponível em: <http://g1.globo.com/pernambuco/noticia/2015/09/pf-confirma-fraude-no-leilao-doterreno-do-cais-jose-estelita-no-recife.html>. Acesso em 30.02.2017.

${ }^{11}$ O DU possui um grupo no Facebook e uma fanpage. Fanpages são espaços de discussões mais gerais, os quais apenas moderadores postam e internautas seguem a partir do momento em que a curtem ou a acessam. Já nos grupos, hipótese que verificamos no pré-campo, há uma interação maior. As pessoas participam mais e podem, também, postar neles. Por isso a escolha metodológica de acompanhar apenas o grupo do DU no Facebook.

Revista de Direito da Cidade, vol. 10, no 2. ISSN 2317-7721 pp. 662-689 668 
do post, (II) maneira como está exposto, (III) número de curtidas, (IV) número de comentários, (V) a pessoa que mais comentou, (VI) comentário mais curtido, (VII) autor do post e (VIII) horário do post. Esse procedimento serviu para entender melhor o funcionamento da página do DU e para identificar as pessoas mais atuantes e com maior alcance dentro do grupo durante o período acompanhado. Vale ressaltar que existem algumas ferramentas que extraem informações (Web Scraping) do Facebook, como o Netvizz e o R. Ao pesquisador, resta verificar se tais instrumentos fornecem as informações que procura.

Num segundo momento entrevistas semiestruturadas foram realizadas com seis moderadores (ou ex-moderadores) do DU - os quais eram possivelmente "líderes"-, escolhidos através da técnica Bola de Neve, e quatro participantes atuantes do DU, identificados através do acompanhamento diário da página do DU no Facebook. A Bola de Neve é uma amostra onde os participantes iniciais indicam novos; estes, por sua vez, sugerem outros novos participantes, e assim sucessivamente, até que seja alcançado o ponto de saturação e o objetivo proposto.

Aos seis possíveis "líderes" do DU também se aplicou um questionário fechado, dividido em duas partes. A primeira recolheu informações socioeconômicas dos líderes, enquanto a segunda dados acerca dos internautas com os quais esses atores centrais mais se relacionavam. O objetivo geral do questionário foi identificar as redes primárias dos moderadores/ex-moderadores dentro do DU, verificando medidas de centralidade da ARS (que mensuram, entre outras coisas, a localização estratégica e a influência de um determinado ator numa rede). A Figura 1 resume o desenho da pesquisa.

\section{Figura 1 - 0 desenho da pesquisa}




\section{CORPUS DA PESQUISA}

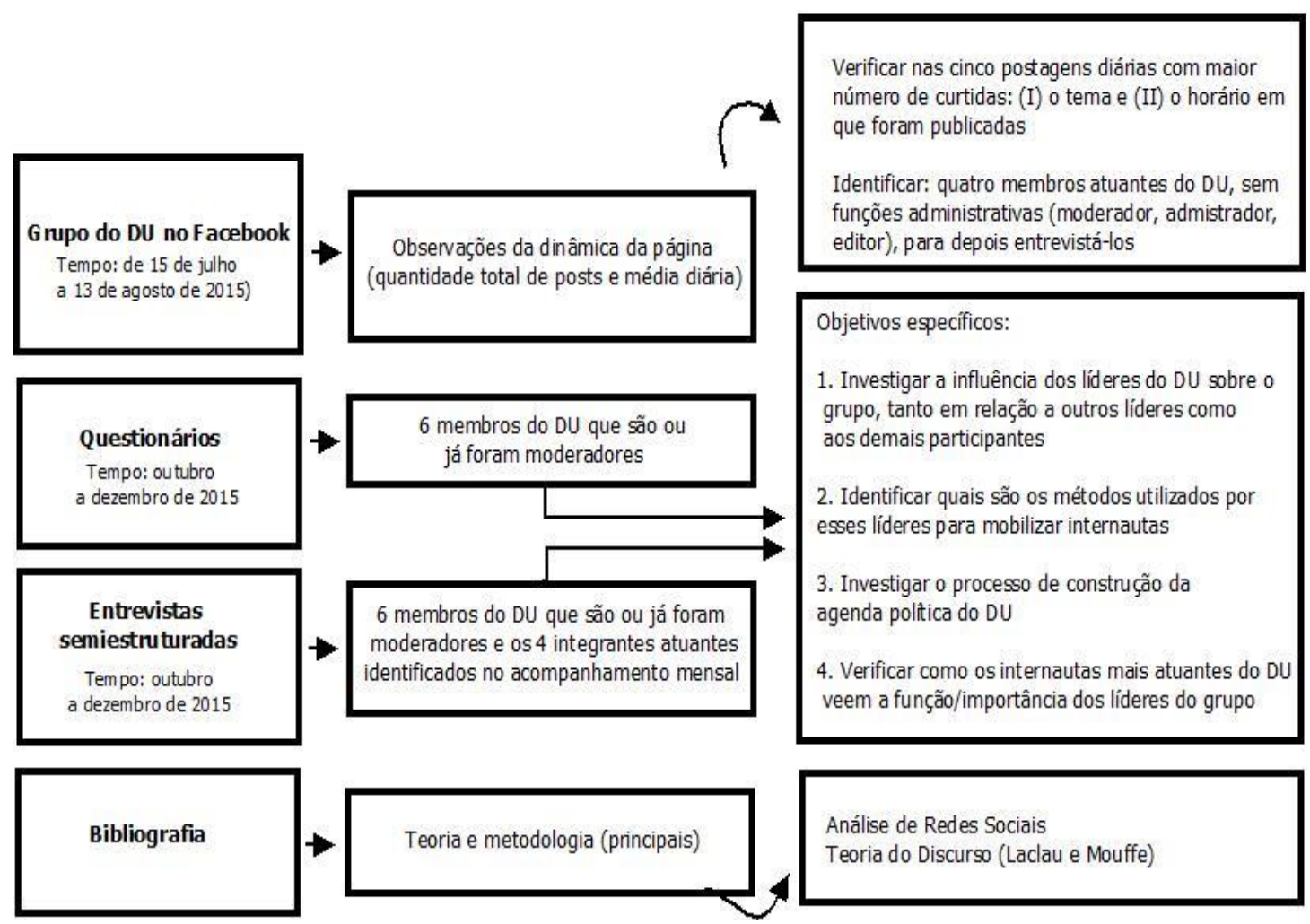

Elaborada no Dia Portable.

\section{A análise de dados}

Entre 15 de julho e 13 de agosto de 2015 foram realizadas 958 postagens na página do DU no Facebook ${ }^{12}$, média de 31,93 por dia. O dia da semana com maior média de postagens foi a quinta-feira (37 posts), enquanto o menor foi domingo (23 posts). Os números mostram que o DU é mais ativo durante a semana. As 150 postagens analisadas do DU nesta pesquisa receberam juntas 20.411 curtidas, média de 136,07 curtidas por cada. A faixa de horário que concentrou o maior número de postagens foi a tarde, entre as $12 \mathrm{~h} 01$ e $18 \mathrm{~h}$.

\footnotetext{
12 Vale ressaltar que no período analisado não houve nenhum fato muito atípico no Recife ou decisão polêmica em relação ao PNR. Assim que, embora não seja possível afirmar, imagina-se que em períodos pré ou pós-decisões polêmicas na cidade a atividade do grupo seja maior.
}

Revista de Direito da Cidade, vol. 10, no 2. ISSN 2317-7721 pp. 662-689 
A escolha dos moderadores/ex-moderadores ${ }^{13}$ do grupo que apresentavam perfis de liderança foi feita através da Bola de Neve, como mencionado, a partir da informante privilegiada $\mathrm{Apau}^{14}$, escolhida por ser uma participante bastante presente na página do DU no Facebook, ser fundadora do grupo e ser um dos membros que representa o DU em entrevistas à imprensa.

Quadro 1 - Os moderadores e ex-moderadores entrevistados do DU

\begin{tabular}{|c|c|c|c|c|c|c|}
\hline Nome/Apelido & Ctav & Lalv & Apau & Merl & Nfau & Clac \\
\hline Sexo & Masculino & Masculino & Feminino & Masculino & Feminino & Feminino \\
\hline Idade & 50 anos & 30 anos & 54 anos & 31 anos & 49 anos & 36 anos \\
\hline $\begin{array}{c}\text { Nível de } \\
\text { escolaridade }\end{array}$ & $\begin{array}{l}\text { Superior } \\
\text { completo }\end{array}$ & $\begin{array}{l}\text { Superior } \\
\text { completo }\end{array}$ & $\begin{array}{c}\text { Superior } \\
\text { completo } \\
\text { (com } \\
\text { doutorado) }\end{array}$ & $\begin{array}{c}\text { Superior } \\
\text { completo } \\
\text { (mestrando) }\end{array}$ & $\begin{array}{l}\text { Superior } \\
\text { completo }\end{array}$ & $\begin{array}{l}\text { Superior } \\
\text { completo } \\
\text { (com } \\
\text { mestrado) }\end{array}$ \\
\hline Posição política & Progressista & Progressista & Progressista & Progressista & Progressista & Progressista \\
\hline Classe social & Média & Média alta & Média & Média & Média & Média alta \\
\hline $\begin{array}{c}\text { Renda mensal } \\
\text { da família (com } \\
\text { salário mínimo a } \\
\text { R\$ 788) }\end{array}$ & $\begin{array}{l}4 \text { a } 10 \\
\text { Salários } \\
\text { mínimos }\end{array}$ & 10 a 20 SM & 4 a $10 \mathrm{SM}$ & 2 a $4 \mathrm{SM}$ & $\begin{array}{c}\text { Acima de } 20 \\
\text { SM }\end{array}$ & $\begin{array}{c}\text { Acima de } 20 \\
\text { SM }\end{array}$ \\
\hline $\begin{array}{l}\text { Domicílio de } \\
\text { nascimento }\end{array}$ & Recife & Recife & Recife & Recife & Recife & Recife \\
\hline $\begin{array}{l}\text { Região onde } \\
\text { reside }\end{array}$ & $\begin{array}{c}\text { Zona Norte } \\
\text { do Recife }\end{array}$ & $\begin{array}{c}\text { Zona Norte } \\
\text { do Recife }\end{array}$ & $\begin{array}{c}\text { Zona Norte } \\
\text { do Recife }\end{array}$ & $\begin{array}{c}\text { Zona Norte } \\
\text { do Recife }\end{array}$ & $\begin{array}{l}\text { Centro do } \\
\text { Recife }\end{array}$ & $\begin{array}{c}\text { Zona Norte } \\
\text { do Recife }\end{array}$ \\
\hline Estado conjugal & $\begin{array}{l}\text { União } \\
\text { estável }\end{array}$ & $\begin{array}{l}\text { União } \\
\text { estável }\end{array}$ & Solteira & Solteiro & $\begin{array}{l}\text { União } \\
\text { estável }\end{array}$ & Separada \\
\hline
\end{tabular}

Fonte: Pesquisa própria. Quadro elaborado pelos autores.

Nota: Dados coletados através de questionários para traçar o perfil dos entrevistados. Vale frisar que as respostas estão exatamente como os entrevistados responderam.

O Quadro 1 traz informações relevantes. Primeiramente, destaque para o nível de escolaridade dos atores, todos com nível superior e alguns com mestrado e doutorado. Em segundo lugar, chamou atenção a região do Recife onde essas pessoas moravam, cinco na Zona Norte do Recife e uma na Área Central ${ }^{15}$. Por último, destaque para a classe social dessas pessoas. Das seis,

13 Incluímos também nesta lista alguns ex-moderadores que, embora estivessem afastados desta tarefa, ainda são bastante influentes no grupo, recebendo reconhecimento dos demais.

${ }^{14}$ Os nomes das pessoas foram deliberadamente omitidos, substituídos por apelidos.

15 Percebeu-se empiricamente que no Recife, a exemplo de outras cidades, as regiões onde as pessoas residem refletem em alguma medida os seus gostos e personalidades; e, assim, as maneiras de ver/lidar com

Revista de Direito da Cidade, vol. 10, no 2. ISSN 2317-7721 pp. 662-689 671 
quatro disseram ser classe média e duas da classe média alta, indício de que o "núcleo duro" do DU seria composto por pessoas com bons rendimentos e escolaridade.

Quanto à rede dos membros do DU mais próximos a cada um dos seis entrevistados, solicitou-se ao entrevistado que citasse até 15 pessoas com as quais mais se relacionasse dentro do DU; a partir daí, gerou-se uma rede única com as redes egocentradas desses seis entrevistados. A análise dessa rede deu ênfase a medidas de centralidade: grau de centralidade, grau de intermediação e centralidade do autovetor. Estas mensuram as posições estruturais dos membros de uma rede e a maior ou menor capacidade de se comunicar com os demais, ou de intermediar processos comunicativos ${ }^{16}$.

A primeira rede formada (Figura 2) é dos membros do DU que foram citados pelos entrevistados ${ }^{17}$.

\section{Figura 2 - Os internautas do DU que mais interagem com os líderes entrevistados. Nota: Nesta rede, os "nós" verdes são os entrevistados que fizeram parte da nossa amostra e os azuis são os citados pelos verdes.}

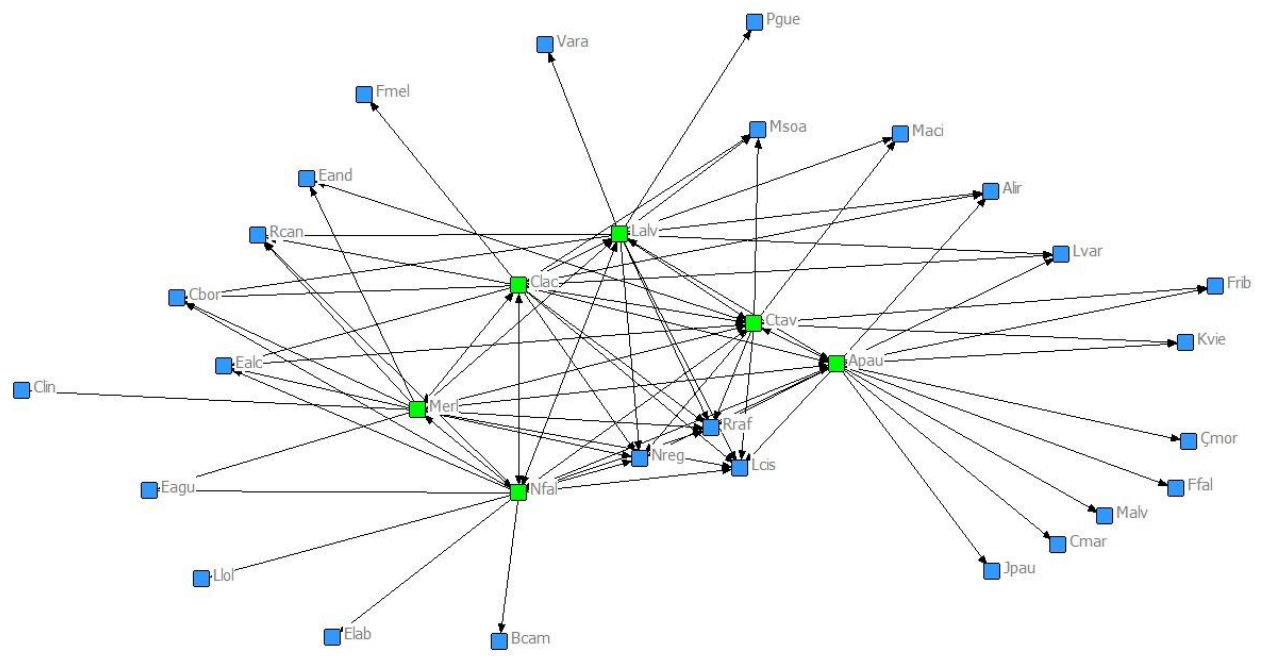

Fonte: Pesquisa própria. Figura elaborada pelos autores. Elaborada no Netdraw.

os problemas do município. Essa informação, embora seja bastante sucinta, pode nos indicar que o grupo tem um alto grau de homofilia, repercutindo inclusive territorialmente.

${ }^{16}$ Essas medidas são explicadas em detalhe no tutorial do Unicet feito por Hanneman e Riddle, disponível em: $<$ http://faculty.ucr.edu/ hanneman/nettext/>. Acesso em 13.01.2017. Para detalhes metodológicos na construção desses índices, consultar Wassaman e Faust (1998).

${ }^{17}$ A figura 2 foi feita a partir da questão: "cite até 15 pessoas com as quais você mais interage do DU". 
Essa rede nos permite observar informações relevantes sobre os índices de indegree e outdegree. O outdegree (quantas pessoas foram citadas pelos entrevistados) não apresenta nada de interessante, uma vez que praticamente todos os entrevistados citaram a mesma quantidade de pessoas. Quando, porém, nos deparamos com o indegree (indicando o número de pessoas que receberam indicações), observamos que foram citadas pessoas que não faziam parte da amostra inicial, alguns inclusive não participando diretamente do $D U^{18}$, conforme a Tabela 1.

A análise desses índices nos permite observar tanto, de forma indireta, as posições estruturais dos atores na rede, como também as aberturas para "fora" desta matriz reticular inicial. Porque, além dos seis entrevistados, a rede se estende para outros, não inscritos originalmente na matriz. Pode-se, com isso, inferir que a rede se estende para além dos limites dos atores centrais; possibilitando alianças estratégicas com atores de outros movimentos e segmentos da sociedade civil.

\section{Tabela 1 - Indegree e outdegree dos atores inscritos no sociograma da Figura 2}

\begin{tabular}{|c|c|c|}
\hline Ator & Outdegree & Indegree \\
\hline Lalv & 15,000 & 5,000 \\
\hline Apau & 15,000 & 5,000 \\
\hline Nfal & 15,000 & 5,000 \\
\hline Ctav & 14,000 & 5,000 \\
\hline Clac & 15,000 & 4,000 \\
\hline Merl & 14,000 & 3,000 \\
\hline Rraf & 0,000 & 6,000 \\
\hline Lcis & 0,000 & 6,000 \\
\hline Nreg & 0,000 & 6,000 \\
\hline Cbor & 0,000 & 4,000 \\
\hline Rcan & 0,000 & 4,000 \\
\hline Ealc & 0,000 & 4,000 \\
\hline
\end{tabular}

Fonte: Pesquisa própria. Tabela elaborada pelos autores.

O segundo índice de rede analisado foi o grau de intermediação (betweenness), o qual mensura a quantidade de vezes que um "nó" pode intermediar relações.

\footnotetext{
${ }^{18}$ A participação direta aqui é indicada pelo fato de as pessoas serem moderadores do grupo, quer dizer, que indicam agendas, que podem eventualmente exercer o poder de censura sobre comentários postados julgados inoportunos etc.
} 
Tabela 2 - Graus de intermediação da figura 2

\begin{tabular}{|c|c|}
\hline Nome do nó & Grau de intermediação \\
\hline Apau & 31.000 \\
\hline Nfal & 22.667 \\
\hline Lalv & 17.333 \\
\hline Ctav & 13.333 \\
\hline Clac & 9.167 \\
\hline Merl & 7.500 \\
\hline
\end{tabular}

Fonte: Pesquisa própria. Tabela elaborada pelos autores

Na tabela 02, vê-se que Apau foi o ator com melhor betweenness (31.000), o que significa que, dos seis entrevistados, Apau tem a maior capacidade de intermediar contato entre eles; e que é o ator que intermedeia mais contatos para fora da rede original (os contatos assinalados abaixo em cor laranja), servindo com certeza de ponte para outros atores, e introduzindo estes atores no campo reticular mais específico dos líderes do movimento DU.

Figura 3 - Comparação entre a mesma rede "com" e "sem" a presença de Apau. Nota: à esquerda, a rede com a presença do "nó" Apau (quadrado preto) e com os cinco "nós" (cor de laranja) aos quais Apau tem acesso. À direita, a mesma rede sem a presença de Apau e suas ligações.
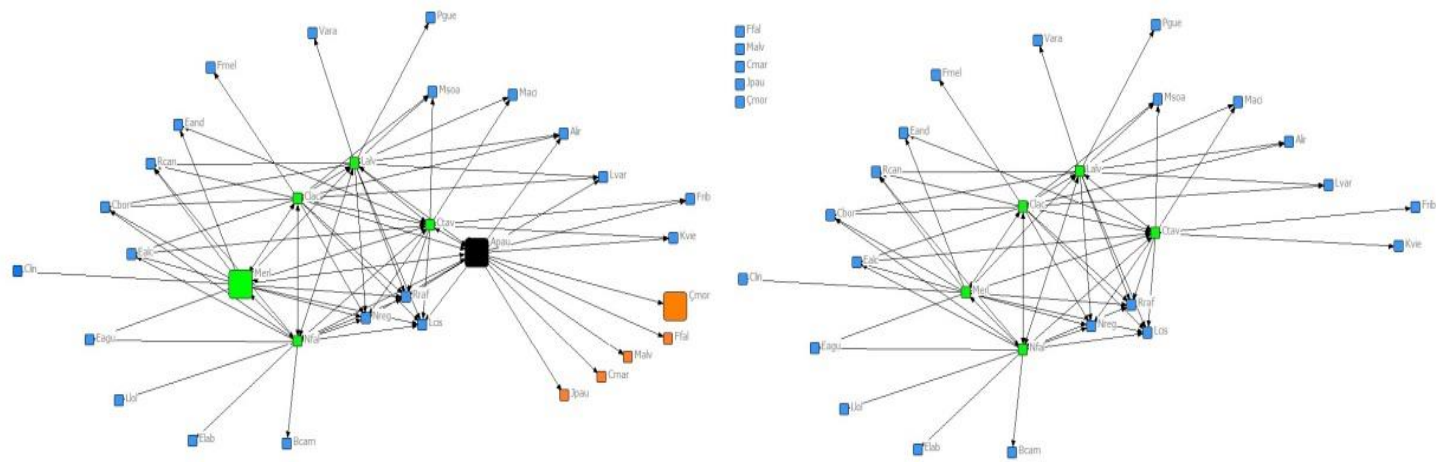

Fonte: Pesquisa própria. Tabela elaborada pelos autores.

Os dados reticulares apresentados nos dão informações sobre as redes egocentradas dos líderes do movimento, caracterizados antes por serem predominantemente de classe média, com formação universitária, residindo majoritariamente na Zona Norte do Recife. Referidas informações podem refletir a estrutura reticular desses atores, com sinais claros de homofilia, conceito que, na 
teoria de redes, significa a tendência na qual os indivíduos têm de se relacionar com pessoas parecidas, do mesmo círculo social e com gostos semelhantes (CHRISTAKIS,2009).

Também nos permitiu constatar que a rede apresenta uma estrutura assimétrica, com posições dos atores hierarquizadas. É uma rede centralizada, com atores mais ou menos posicionados na estrutura da rede e consequentemente com maior ou menor influência em seu interior, e com laços para o exterior do campo reticular mais ou menos importantes. Embora seja uma panela ${ }^{19}$, as conexões dos atores se estendem para além do clique, incluindo outros não presentes no círculo original. Isso é observado a partir de atores - fora do núcleo central da rede que foram mais citados, com índices de outdegree visivelmente superiores ao de alguns "líderes" entrevistados. O que permite também considerar que alguns atores localizados no subset reticular original apresentam maior capacidade de estabelecer ligações intensas com o ambiente - e, portanto, controlar os fluxos comunicativos em frente a outros atores.

Vale a ressalva que apresentamos dados reticulares de uma rede formada pelos líderes do movimento entrevistados, e que, para uma melhor compreensão do processo de mobilização do DU, teríamos que ter mais informações sobre o campo reticular mais vasto, incluindo os participantes ocasionais.

A análise continua com as entrevistas realizadas com membros do DU. Foram realizadas entrevistas semiestruturadas aplicadas com dez membros do DU, realizadas entre setembro e novembro de 2015. Além dos seis moderadores/ex-moderadores do DU, também entrevistamos quatro atores atuantes do grupo identificados a partir do acompanhamento mensal da página no Facebook.

Para analisar as entrevistas com os moderadores/ex-moderadores do DU foram criadas categorias analíticas objetivando esclarecer algumas questões relativas à dinâmica do movimento DU. As categorias de análise utilizadas seguem no Quadro 2.

\footnotetext{
${ }^{19}$ Redes ou subgrafos fortemente ligados entre si, com poucas articulações fora do círculo mais restrito. A literatura de língua inglesa se refere a esse fenômeno utilizando a expressão "clique", definida como: um subgrafo de três ou mais nodos, todos adjacentes, não existindo algum que não seja adjacente à totalidade dos membros do clique.
} 


\section{Quadro 2 - Campos Discursivos de participantes do DU}

\begin{tabular}{|c|c|c|}
\hline Questões a analisar & $\begin{array}{c}\text { Categoria de } \\
\text { análise a ser } \\
\text { observada }\end{array}$ & Trechos centrais da fala dos entrevistados \\
\hline $\begin{array}{c}\text { A contribuição dos líderes do DU } \\
\text { para o grupo e participantes }\end{array}$ & Trajetória & $\begin{array}{l}\text { - História dos líderes (trajetória em outros } \\
\text { movimentos sociais e evolução no DU) } \\
\text { - Contribuição ao DU (formação de cada líder e } \\
\text { recursos humanos disponíveis) }\end{array}$ \\
\hline $\begin{array}{l}\text { Métodos utilizados pelos líderes } \\
\text { do grupo para mobilizar } \\
\text { participantes }\end{array}$ & Articulação & $\begin{array}{c}\text { - Mecanismos de articulação do grupo (reuniões, } \\
\text { articulação dos líderes para mobilizar pessoas e } \\
\text { relação com outros coletivos) }\end{array}$ \\
\hline $\begin{array}{l}\text { Processo de construção da agenda } \\
\text { política do grupo (identificar e } \\
\text { definir quais as agendas) }\end{array}$ & Mobilização & $\begin{array}{c}\text { - Mobilização de pessoas (o que motiva a ação } \\
\text { coletiva?) } \\
\text { - Conquistas do DU (vaga no Conselho da Cidade } \\
\text { do Recife, não construção dos viadutos da } \\
\text { Avenida Agamenon Magalhães, Ocupe Estelita } \\
\text { etc.) }\end{array}$ \\
\hline
\end{tabular}

Fonte: Cavalcanti (2016).

A organização dos campos discursivos dos atores do DU criou um caminho para se entender o papel dos líderes na ação coletiva. As análises levaram em consideração dois problemas: (I) as "racionalizações retrospectivas", quando os entrevistados de movimentos sociais articulam frases que estão de acordo com as versões que alimentam o discurso do movimento; e as (II) "representações hiperbólicas", quando o passado e o presente são descritos de maneira demasiada otimista ou pessimista pelo entrevistado (HOWARD, 2005). Além das questões contempladas no Quadro 2, outras foram abordadas para investigar (I) como os entrevistados viam a estrutura do DU, (II) se acreditavam na existência de lideranças no grupo e (III) o que pensavam sobre o papel da moderação.

Em relação à estrutura do DU, os entrevistados relataram que é precária e funciona de maneira espontânea e voluntariosa. Um comentário que chamou a atenção foi o de Lalv, ao explicar que o DU tem duas frentes de atuação, o "grupão" e o "núcleo duro". Segundo ele, o primeiro é o canal de divulgação do grupo, onde os mais de 31 mil membros podem participar; já o segundo é restrito, prevalecendo a confiança por trabalhar com temas sigilosos e sensíveis.

Acerca da existência de lideranças, a opinião dos entrevistados ficou dividida. Três disseram que "há líderes no DU" (Apau, Nfau e Lalv), dois que "não existem" (Merl e Clac) e um (Ctav) apenas 
reconheceu que a "horizontalidade absoluta" é utópica. Percebeu-se, no entanto, que a palavra "líder", talvez pelo que traga consigo no seu extradiscursivo, por vezes era evitada, a exemplo de quando Ctav usou a expressão "pessoas de referência".

No que se refere às funções da moderação, a fala de Clac talvez seja a que resumiu melhor essa questão. Segundo ela, a moderação tem como papel envolver o grupo na principal pauta do DU, o direito à cidade, o qual explicou o que pode ser (temas de legislação urbanística, mobilidade, meio ambiente, desenvolvimento urbano, etc.) e o que não é (algum caso de corrupção em Brasília, por exemplo). Ao definir isso, Clac apontou, quiçá, para a principal função da moderação, buscar unir diferentes atores sociais em torno do tema direito à cidade.

As falas dos entrevistados foram decompostas em três grupos: (a) trajetória; (b) articulação e (c) mobilização. Esses três campos discursivos nos permitem investigar detalhadamente as nuances do processo de ação coletiva do DU, tal como percebem os seus "líderes". São, naturalmente, representações recortadas por visões de mundo que talvez não correspondam nem mesmo àquela construída pela maioria de seus 31 mil membros. Mas são importantes campos discursivos, na medida em que, enquanto líderes, estas pessoas têm poder de mediar, filtrar e provocar agendas.

\section{TRAJETÓRIA}

Consideramos, para esse item, duas questões centrais: (a) história dos líderes e a (b) contribuição ao DU. Solicitou-se aos entrevistados que discorressem sobre sua inserção no DU. Falar sobre trajetórias de ativistas políticos significa lembrar os itinerários de socialização política que o levaram ao movimento, experiências que, posteriormente, instrumentalizaram-se em capital político. Embora os atributos individuais do líder sejam importantes (carisma, capacidade de mobilização, agilidade em tomar decisões etc.), as posições dos atores em uma estrutura reticular contribuem significativamente para o acesso a possibilidades de aprendizado e inserção em campos de luta.

As trajetórias de socialização política e de recrutamento são, na maior parte dos casos, semelhantes para os ativistas on-line e os que não fazem uso dos recursos da Internet. Mas existem algumas particularidades, como, por exemplo, o fato bastante comum de que os laços on-line se sobrepõem aos estabelecidos em contatos face a face - quer dizer, pessoas normalmente 
conhecem as pessoas com quem mantêm contato via internet; ou, o que também é comum, campos reticulares estabelecendo pontes; ou relés (FONTES, 2007) para círculos sociais antes distantes.

Ainda existem os casos relativamente únicos, quando o contato com o grupo virtual é feito a partir de "sugestão" do próprio Facebook, como é o caso de Lalv, que ingressou no Facebook por indicação da própria rede americana, a qual através de algoritmos faz uma seleção de conteúdos (com sugestão de amizades, grupos, produtos para comprar etc.) para aparecer no feed notícias dos usuários. Não se sabe ainda muito bem como esses algoritmos são elaborados e funcionam, mas tudo indica que levam em consideração ações no Facebook, como curtidas em fotos e acesso a páginas/pessoas, verificando aspectos como comentários e compartilhamentos.

Outros entrevistados entraram no DU através de contatos no Facebook, caso de Nfal, que ingressou no DU a convite de uma amiga logo após criar uma conta na rede social norte-americana. Aos poucos, Nfal foi ficando conhecida no DU e num dia um dos integrantes mais ativos puxou conversa com ela por inbox (chat para conversas pessoais do Facebook) convidando-a para ser moderadora.

A transterritorialidade do DU também é interessante. A designer Clac começou a participar do grupo a mais de três mil quilômetros de distância de onde o grupo nasceu. Recifense, Clac passou num concurso em Porto Alegre e morava lá quando ingressou no DU, após ter interesse em discussões acerca da demolição do prédio Caiçara e da Lei Marília Arraes. Retomando ao Recife, Clac participou de protestos organizados pelo DU e aproximou-se de um subgrupo menor mais ligado à tecnologia, o dos "nerds", como chamou. Depois de se destacar nesse pequeno grupo, foi convidada para ser moderadora. Nesse ponto da trajetória de Clac, chama a atenção um cluster (grupo social reduzido) da rede dela, o grupo dos "nerds"; afinal, no fim, o DU é uma rede social constituída por vários clusters (BATISTA, 2015).

Os únicos fundadores do DU entrevistados foram Apau e Ctav. A primeira participa desde os 17 anos de movimentos sociais, entre eles o movimento estudantil e o feminista. Além disso, foi uma das fundadoras do PT em Pernambuco. Diferentemente de Apau, Ctav nunca tinha participado de movimento social, mas interessou-se sempre por política, definindo-se como "de esquerda".

Os entrevistados disseram que geralmente contribuem ao DU com a sua especialidade (formação em direito, comunicação, design, arquitetura etc.), mas que essa contribuição depende 
muito do tempo disponível. Ao longo das entrevistas, a intensidade da participação no DU foi identificada como importante para ganhar espaço no grupo. Não à toa, os membros considerados com maior influência sobre os internautas pelos moderadores e ex-moderadores entrevistados foram os que mais postaram no grupo no período acompanhado pela pesquisa.

Segundo os entrevistados, cada membro do "núcleo duro" do DU tem algumas tarefas prédefinidas. Entre outras coisas, as entrevistas mostraram que Ctav contribui com a sua rede de contatos e indo ao MP; Apau com a sua boa relação com outros movimentos sociais; Nfal postando informações no DU e gerando pautas; Clac trazendo informações de tecnologia e fazendo pontes com o universo digital; Merl com os seus conhecimentos em arquitetura e urbanismo; e Lalv com a sua rede de contatos e experiência em ações junto ao MP.

\section{ARTICULAÇÃO}

Para promover a ação coletiva o DU precisa articular as pessoas em torno de uma causa em comum. Com empenho e atos bem dirigidos, a mobilização torna-se viável. A articulação é, desta forma, ao lado da mobilização - como veremos mais adiante - um dos fatores centrais para o sucesso do movimento. Neste sentido, são empreendidas ações objetivando promover as agendas centrais do movimento, com a necessária comunicação com a esfera pública e seus diversos atores (imprensa, movimentos sociais, sindicatos, entre outros).

Enquanto grupo, o DU tem uma temática central que é discutir o direito à cidade e questões de patrimônio histórico, o que tem muito haver com o seu surgimento. Acontece que o DU foi se expandindo e passou a ser "um muro de lamentações", como alguns membros relataram (Clac e Merl). Nesse processo, o papel dos líderes é exatamente o de extrair o máximo de interessante do que é postado no "grupão" e de planejar bem as ações (se é necessário entrar na justiça ou não, por exemplo).

Periodicamente, a agenda política do DU e as ações realizadas são discutidas no "núcleo duro" do grupo, uma espécie de balanço para se tratar o que vai seguir em frente e o que deve parar. Além disso, a própria noção do que é direito à cidade vai se ampliando, e novas pautas e demandas podem entrar no DU, como informou Merl, ao destacar que acredita que questões de gênero e de raça no Recife, "que a princípio não eram pautas do DU", atualmente "poderiam ser". Essas mudanças podem demandar um pouco de tempo, uma vez que dependem da própria 
transformação dos movimentos sociais, espécies de alvos em movimento (CASTELLS, 2003).

Como já observado, a plataforma do DU é aberta e qualquer internauta que está no grupo pode postar, com algumas questões rendendo mais do que outras. Segundo Apau, as pessoas que se mobilizam, em geral, são aquelas mais próximas ao problema. Assim, a moderação do DU tenta colaborar com coletivos e pessoas interessadas em assuntos relacionados à pauta do DU, para depois deixá-los seguirem sozinhos.

Os atores mais centrais do DU se reúnem em vários chats internos no processo articulatório. O que agrega mais membros tem cerca de 40 pessoas, mas Apau mencionou que a ideia é ter ainda mais gente, para aumentar o poder de atuação. Dentro do DU também há vários outros coletivos e representantes de movimentos sociais ${ }^{20}$.

\section{MOBILIZAÇÃO}

Quais são as condições para a mobilização? O que faz com que se mobilize? Entre outros fatores, a mobilização depende da capacidade de mobilização de recursos, dos custos, do empenho dos atores envolvidos na ação e de um discurso sólido e convincente de um indivíduo ou grupo de pessoas. Isso sem contar nas condições políticas necessárias e no relacionamento com outros movimentos sociais, muitas vezes fatores também fundamentais para uma ação bem sucedida, conforme bem apontou a Teoria do Processo Político (ALONSO, 2009).

Questionado sobre o tema mobilização, Merl disse que nunca refletiu sobre o assunto fora do DU. Dentro do grupo, contudo, observa que o ponto de partida é dado quando os membros começam a acreditar que a realidade (uma cidade melhor, por exemplo) pode se concretizar através da união de atores, ou seja, a compreensão de que um coletivo de indivíduos engajados tem força para promover mudanças sociais. Nesse processo, a ida à rua tem uma grande pressão sobre o poder público, complementou Merl. Assim, a fala de Merl leva a compreensão de que o nível de interesse pelas pautas por parte dos integrantes de um grupo virtual e o engajamento destes numa ação tradicional (passeatas, abaixo-assinados, atos públicos etc.) faz parte do processo de mobilização.

20 Levantamento feito por Oliveira (2013) apontou que estão no DU: Escambo Coletivo, Mídia Lunar, Pernambuco Sustentável, Produtor Culturalpe, DCE Unicape, Muda Direito, Marcha da Maconha Olinda, Revocultura, Amigos do Mangue, Folhetim Bicicletada, Tatuí Crítica de Arte, Fórum da Música, Dacs UFPE etc.

Revista de Direito da Cidade, vol. 10, no 2. ISSN 2317-7721 pp. 662-689 680 
Clac acrescentou que o DU tem algumas bandeiras que sempre provocaram muita discussão, a exemplo de mobilidade e preservação do patrimônio histórico. Já Ctav, por sua vez, frisou as diferenças do DU em relação às formas de atuação dos movimentos tradicionais, sendo diferente por manter uma plataforma de debate e ao mesmo tempo de distribuição de conteúdo, o que não se tem "normalmente associado a movimentos sociais", nos quais geralmente as pessoas possuem as pautas e depois as "disseminam em campanhas".

A literatura aponta que para que a mobilização ocorra é preciso de pautas e de um discurso. Na Teoria do Discurso, o discurso destaca-se pelo princípio do descentramento do sujeito, uma vez que as complexidades das relações contemporâneas colocaram em xeque um centro fixo, constituidor de identidades. Nesse sentido, o discurso - composto por estruturas descentradas, com sentidos constantemente sendo negociados e construídos (MUTZENBERG, 2003) - é o terreno primário onde a realidade se constitui, tomando o pressuposto de que a linguagem é constituidora da realidade.

Mas para o discurso ser formado, é preciso a prática articulatória, processo no qual os elementos (formações discursivas ainda não articuladas e dispersas) buscam se tornar momentos provisórios de sentido, ou seja, articulam-se em torno de pontos nodais através de cadeias de equivalência até chegar ao discurso (as demandas propriamente ditas).

Pensando no movimento Ocupe Estelita (antes organizado pelo DU e hoje funcionando de maneira mais independente), podemos imaginar um grupo com indivíduos (o DU, à época) com inúmeras ideias desarticuladas e reivindicações (tais como qualidade de vida ruim, ruas esburacadas, gentrificação da cidade etc.). Aí surge o Projeto Novo Recife, como exterior e ponto antagônico, o qual precisa de um discurso contra ele. É quando, através de cadeias de equivalências, os elementos se transformam em momentos provisórios discursivos, em torno do ponto nodal direito à cidade. Daí ocorre a lógica da hegemonia, que representa a prática de construção de alianças e coalizões políticas entre diferentes atores sociais e demandas em um discurso comum, para construir um sujeito político mais universal. Além do DU, essa lógica é observada na atuação de outros movimentos políticos brasileiros de esquerda (COSTA; PRADO, 2011).

Neste campo, também é interessante observar o fato de que as redes se estruturam em subgrafos, integrados entre si, e com campos de sociabilidade distintos. A importância dos líderes, 
ou atores centrais, consiste exatamente em formar pontes entre diversos campos reticulares, permitindo a mobilização de atores variados, às vezes com interesses específicos, mas mobilizados em torno de uma bandeira única.

Outro ponto que merece destaque diz respeito aos métodos utilizados pelos líderes do DU para mobilizar participantes, que podem ser de naturezas diversas: a) participam de chats específicos para discutir ações estratégicas, b) costumam realizar postagens com frequência ou em momentos de maior mobilização, c) tentam manter o debate dentro da pertinência temática e, talvez o mais importante, d) buscam um discurso único em torno de um ponto nodal que aglomere os mais diversos atores e grupos sociais (cientes previamente das pautas que atraem mais pessoas).

Finalmente, há que assinalar a forma como as agendas políticas são gestadas. Nesse sentido, constatou-se que as pautas podem vir de diversos lugares, como do "grupão" ou de reportagens de periódicos. Porém, um caminho recorrente é os temas serem debatidos no "grupão" e, em paralelo, discutidos em chats privados do "núcleo duro", onde as ações são planejadas. Observou-se ademais que, segundo os entrevistados, as principais pautas do DU estão relacionadas à mobilidade urbana e à preservação do patrimônio histórico do Recife, o que também se constatou no acompanhamento mensal do DU.

\section{CONSIDERAÇÕES FINAIS}

Ao terminar este trabalho, registra-se a importância de dar continuidade a estudos sobre questões aqui abordadas. Afinal, entre os desafios dos pesquisadores digitais do século XXI certamente está compreender e acompanhar o processo de inovações tecnológicas, tanto de (I) aparelhos (smartphones, PCs, TVs etc.) como de (II) redes e aplicativos virtuais (Twitter, Whatsapp, Snapchat, Instagram, Facebook, Linkedln etc.) que se desenvolvem a todo instante num mundo cada vez mais interconectado.

Como principais dificuldades da pesquisa, destaca-se o fato de ser bastante complicado acessar informações em grupos ativos no Facebook (com um grande número de postagens). No caso do DU, por exemplo, postagens com mais de cinco meses foram praticamente impossíveis de ser encontradas, uma vez que, ao carregar um elevado número de publicações através da barra de rolagem (scrollbar), a página do DU simplesmente saia do ar de tanta informação. Nesse sentido, isso prejudicou propostas iniciais desta pesquisa, como a de verificar a dinâmica do DU em períodos

Revista de Direito da Cidade, vol. 10, № 2. ISSN 2317-7721 pp. 662-689 682 
movimentados em anos anteriores. Uma sugestão para quem almeja fazer análises documentais ou em tempo real no Facebook é tirar prints e salvar os documentos mais importantes.

Como ponto positivo, registra-se a possibilidade de obter boas informações para análise através da união da ARS e de entrevistas semiestruturadas. A primeira, como demonstrado, permite (I) identificar diversas relações estabelecidas entre atores, com um diverso leque de medidas (centralidade, densidade etc.) que podem ser exploradas, (II) enquanto a segunda fornece informações discursivas que ajudam a compreender e analisar essas relações.

Entre os resultados da pesquisa, destacaram-se a (I) tendência a qual os membros do DU têm de se relacionar com pessoas de círculos sociais parecidos e (II) a identificação de ações dos líderes do DU para mobilizar internautas, tais como a) chats específicos para discutir estratégias, b) sugestão de pautas através de postagens, c) manutenção do debate dentro da pertinência temática (filtragem de conteúdo), d) bom relacionamento com outros coletivos e e) busca por um discurso único em torno de um ponto nodal que aglomere os mais diversos grupos sociais.

Por fim, vale ressaltar que aqui buscamos responder a um problema de pesquisa delimitado, "como os participantes do DU são mobilizados?", com ênfase em um tipo de metodologia. Porém, outras questões ficaram em aberto, podendo ser respondidas em estudos posteriores. Quais as vantagens e desvantagens de grupos de pressão quando estes se propõem a resolver um problema real? A manifestação cidadã na rede é tão efetiva quanto na praça pública? Essas são perguntas relevantes que se aplicam não apenas ao DU, mas a vários outros grupos políticos nacionais.

Também é importante destacar que existem várias formas de mobilização, a exemplo de movimentos sociais organizadas, marchas e manifestações-bloqueio (SCHERER-WARREN, 2014); e de ativismo, como clique-ativismo, campanhas de apoio on-line e plataformas de consulta. Nesse sentido, o momento atual é promissor para pesquisas no universo virtual, diante de tantas estratégias de ação coletiva distintas. Ao pesquisador da era digital, existe a vantagem de termos várias ferramentas para coleta de dados em mídias digitais à disposição, como R e Netvizz para o Facebook, Remid para o Twitter e NodeXL para o Flickr, Youtube e Twitter (RECUERO, 2014). Uma vez com os dados em mãos, resta-nos escolher um meio/método para analisá-los. 


\section{REFERÊNCIAS BIBLIOGRÁFICAS}

ALEZANDRO, Velázquez; NORMAN, Aguillar. Manual introdutório à análise de redes sociais. Mexico: Universidad Autonoma Del Estado de México. Tradução e adaptação de: Maria Luísa Lebres Aires, Joanne Brás Laranjeiro e Sílvia Cláudia de Almeida Silva, 2006. Disponível em: <http://docplayer.com.br/4895662-Manual-introdutorio-a-analise-de-redes-sociais.html>. Acesso em 08.02.2017.

ALl et al. Occupy: movimentos de protesto que tomaram as ruas. São Paulo: Boitempo Editorial, 2012.

BARABÁSI, Albert. Linked - a nova ciência dos networks. São Paulo: Leopardo editora, 2009.

BATISTA, Micheline. Entre a rede e a comunidade: interação e comunicação nos grupos do Facebook - o caso do Direitos Urbanos/Recife. Tese de doutorado, Universidade Federal de Pernambuco, 2015.

CASTELLS, Manuel. A galáxia da internet: reflexões sobre a internet, os negócios e a socieidade. Rio de Janeiro, Jorge Zahar Ed, 2003.

(2013) Redes de indignação e esperança. Rio de Janeiro: Zahar editora.

COSTA, Frederico; PRADO, Marco. Estratégia de articulação e estratégia de aliança: possibilidades para a luta política. Revista Sociedade e Estado, Brasília, vol. 26, no 3, 2011.

CHRISTAKIS, Nikolas. Connected: the surprising Power of our social networks and how they shape our lives. New York: Little Brown Co, 2009.

DONK, D.V.W; LOADER, D.B; NIXON, G.P; RUCHT, D. (eds.) Cyberprotest - New Media, Citizens and Social Movements. London: Routledge, 2004.

EICHNER, K. et al. A análise de redes sociais e ação coletiva: a comunidade científica de analistas de redes lusófonos. In: Maria Inês Tomael e Regina Marteleto (eds.), Informação e redes sociais: interfaces de teorias, métodos e objetos. Londrina: EDUEL - Editora da Universidade Estadual de Londrina, 1a edição, vol. 1, 2015.2 Disponível em: <http://www.revista.ufpe.br/revsocio/index.php/revista/article/view/504/394>. Acesso em 19.03.2017.

FERREIRA, Jonatas; FONTES, Breno. Ágora Eletrônica: algumas reflexões teórico-metodológicas. Estudos de Sociologia, Recife, vol. 14, no 2, 2014. Disponível em: <http://www.revista.ufpe.br/revsocio/index.php/revista/article/view/405/331>. Acesso em 14.04.2017.

FONTES, Breno (2007) A Construção das Redes Sociais de Operadores de ONGs: Os Mecanismos de Recrutamento a Partir das Relés Sociais. REDES - Revista hispana para el análisis de redes sociales, 
vol. 12. Disponível em: <http://revista-redes.rediris.es/html-vol12/Vol12_7.htm>. Acesso em 08.02.2017.

Redes Sociais e Poder Local. Recife: Editora da UFPE, 2012.

Tecendo Redes, Suportando o Sofrimento: sobre os círculos sociais da loucura. Sociologias,

Porto Alegre, vol. 16, no 37, 2014. Disponível em: $<$ http://www.scielo.br/scielo.php?script=sci_arttext\&pid=S1517-

$45222014000300112 \& \operatorname{lng}=e n \& n r m=i s o \& t \operatorname{lng}=p t>$. Acesso em 05.02.2017.

GANZ, Marshall. Leading Change: Leadership, Organization, and Social Movements. Cambridge: Kennedy School of Government, Harvard University, 2008.

GRANOVETTER, Mark. The Strength Of Weak Ties. American Journal of Sociology, vol. 78, no 6, p. 1360-80, 1973.

GUEDES, M. Tais. As redes sociais - Facebook e Twitter - e suas influências nos Movimentos Sociais. Dissertação de mestrado, Universidade de Brasília, 2013.

HOLLSTEIN, Bettina. Qualititative approaches. In: John Scott \& Peter J. Carrington (Eds.), Sage Handbook of Social Network Analysis. London/New Delhi: Sage (forthcoming), 2011.

HOWARD, David. Aplicando la Teoría del Discurso: el Método de la Articulación. Facultad de Ciencia Política y Relaciones Internacionales, de la Universidad Católica de Córdoba, Córdoba, República Argentina, no 5, 2005.

KOZINETS, Robert. Netnography - Doing ethnographic research online. London: Sage Publications Ltd, 2010.

LACLAU, Ernesto; Mouffe, Chantal. Hegemonía y estrategia socialista. Madrid: Siglo XXI, 1987.

LACLAU, Ernesto. O retorno do "povo": razão populista, antagonismo e identidades coletivas. Revista de Ciências Sociais, no 23, p. 09-34, 2005.

MARWELL, Gerald; Oliver, E. Pamela. Social Networks and Collective Action: A Theory of the Critical Mass. American Journal of Sociology, Chicago, vol. 94, no 4, 1989.

MAZZOCATO, M. Sandra. A reconfiguração do sujeito através de sua representação online: as características e os processos no Facebook. Tese de doutorado, Pontificia Universidade Católica do Rio Grande do Sul, 2014

MOLINA, José Luis. El análisis de redes sociales: uma introduccion. Barcelona: Bellaterra, 2001.

MOUFFE, Chantal. Feminismo, ciudadania y politica democratica radical. In: Ciudadanía y feminismo: Feminismo y teoría identidad pública/privada, México, Instituto Federal Eleutoral, 2001. Tradução de Hortensia Moreno de Feminists Theorize the Political, ed. Judith Butler and Joan W. Scott, Routledge, $2001 . \quad$ Disponível em: 
<http://mujeresdelsur.org/sitio/images/descargas/chantal_mouffe\%5B1\%5D.pdf\%20ciudadania\%2 0y\%20feminismo.pdf>. Acesso em 01.02.2017.

MUTZENBERG, Remo. Identidades e movimentos sociais numa sociedade indomável. Política \& Trabalho, Paraíba, 19, Programa de Pós-Graduação em Sociologia (UFPB), 2003.

OLIVEIRA, B. M. Teresa. Articulação de identidades políticas a partir de redes sociais na internet: uma análise a partir do grupo "Direitos Urbanos / Recife" do Facebook. Dissertação de mestrado, Universidade Federal de Pernambuco, 2013.

PUTNAM, Robert. Bowling alone: the collapse and revival of American community. New York: Simon \& Schuster, 2000.

RECUERO, Raquel. Redes sociais na internet. (Coleção Cibercultura). Porto Alegre: Sulina, 2009.

RECUERO, Raquel. Contribuições da Análise de Redes Sociais para o estudo das redes sociais na Internet: o caso da hashtag \#Tamojuntodilma e \#CalaabocaDilma. Revista Fronteiras - estudos midiáticos, pp. 60-77, maio/agosto 2014.

RODRÍGUEZ, A. Josep. Análisis estrutural y de redes. Cuadernos metodológicos, Madri, no 16, 1995.

SCOTT, John. Social Network Analysis (Second edition). London: Sage Publications, 2000.

SOUSA, M. Cidoval; SOUZA A. Arão. (Orgs.) Jornadas de junho: repercussões e leituras. Campina Grande-PB, Eduepb, 2013.

SCHERER-WARREN, Ilse. Dos movimentos sociais às manifestações de rua: o ativismo brasileiro do sec. XXI. Revista Política e Sociedade, Florianópolis, vol. 13, n 28, Set./Dez. de 2014.

THACKER, Eugene. Neworks, Swarms, Multitudes. Part One. Critical Theory, 2004. Disponível em: <http:/www.ctheory.net/articles.aspx?id=422>. Acesso em 04.02.2017.

WATTS, Duncan. Seis Graus de Separação (six degrees). A evolução da ciência de redes em uma era conectada. São Paulo: Leopardo Editora, 2009. 


\section{ANEXO A}

Nome:

Data:

Roteiro para entrevista (perguntas para organizadores do DU)

\begin{tabular}{|c|c|}
\hline Tópico abordado & Pergunta-guia \\
\hline \multirow{5}{*}{$\frac{\text { A trajetória no DU e }}{\text { a atuação no grupo }}$} & $\begin{array}{l}\text { 1. Para começarmos, você pode me falar um pouco da sua trajetória no DU. Quando } \\
\text { você entrou, o que fazia no DU e o que faz agora? }\end{array}$ \\
\hline & $\begin{array}{c}\text { 2. Nessa sua trajetória, desde quando você ingressou no DU até o momento, o que } \\
\text { mudou? }\end{array}$ \\
\hline & \\
\hline & $\begin{array}{c}\text { 3. O DU tem Facebook, Twiter e blog. Em relação às ações do grupo no ambiente } \\
\text { virtual, algumas pessoas específicas tomam conta delas? }\end{array}$ \\
\hline & $\begin{array}{l}\text { 4. Entre as pessoas mais atuantes do DU, são definidas quais são as áreas mais } \\
\text { estratégicas e as maiores demandas do grupo? (por exemplo, a necessidade de mais } \\
\text { empenho na organização de um evento específico ou na aproximação com a } \\
\text { imprensa). Se sim, como isso é feito? }\end{array}$ \\
\hline \multirow{3}{*}{$\frac{\text { Relação com outros }}{\frac{\text { líderes e grupos }}{\underline{\text { virtuais }}}}$} & 5. Como é a sua relação com os outros organizadores do grupo? \\
\hline & 6. Vocês interagem com outros grupos virtuais, trocam ideias? \\
\hline & $\begin{array}{l}\text { 7. Como você avalia as ações do DU no ambiente virtual? (são bem planejadas, } \\
\text { geralmente alcançam seus objetivos, precisam melhorar?) }\end{array}$ \\
\hline \multirow{2}{*}{$\frac{\text { Mobilização de }}{\text { pessoas e recursos }}$} & $\begin{array}{l}\text { 8. Quais são os principais métodos utilizados pelas pessoas mais centrais do DU para } \\
\text { atrair participantes e mobilizá-los em torno de certas pautas? }\end{array}$ \\
\hline & $\begin{array}{l}\text { 9. Para você, quais fatores levam as pessoas do DU a se mobilizarem? (ex.: a) } \\
\text { informam-se no grupo de algo que não sabiam e decidem agir, ou b) são influenciadas, } \\
\text { de alguma maneira, por outros integrantes do grupo }\end{array}$ \\
\hline
\end{tabular}

Revista de Direito da Cidade, vol. 10, no 2. ISSN 2317-7721 pp. 662-689 


\begin{tabular}{|c|c|}
\hline Tópico abordado & Pergunta-guia \\
\hline \multirow{4}{*}{$\frac{\text { Discurso do DU, papel dos }}{\frac{\text { líderes e influência sobre }}{\text { participantes }}}$} & $\begin{array}{l}\text { 10. Temos exemplos de várias mobilizações organizadas pelo DU. Na sua } \\
\text { opinião, como o grupo consegue articular reivindicações/protestos com } \\
\text { sujeitos políticos tão diferentes? }\end{array}$ \\
\hline & $\begin{array}{l}\text { 11. Qual o principal discurso do DU? Na definição das principais demandas } \\
\text { do grupo, como é o processo de construção coletiva desses conteúdos? }\end{array}$ \\
\hline & $\begin{array}{l}\text { 12. Qual é o papel das pessoas mais atuantes do DU na divulgação de } \\
\text { informações? Você acha que o DU tem líderes? }\end{array}$ \\
\hline & $\begin{array}{l}\text { 13. Qual é o papel dessas pessoas sobre os demais participantes e na } \\
\text { mobilização de pessoas? }\end{array}$ \\
\hline \multirow{4}{*}{$\frac{\text { Impressões gerais acerca do }}{\underline{\text { DU }}}$} & 14. Você acha que o DU é um movimento horizontal ou vertical? \\
\hline & $\begin{array}{l}\text { 15. Como você avalia a estrutura do DU (recursos humanos, financeiros e de } \\
\text { comunicação)? }\end{array}$ \\
\hline & $\begin{array}{l}\text { 16. Considera que a sua rede de contatos e o seu conhecimento contribuem } \\
\text { para a construção da agenda política do DU? Por quê? Você acha que } \\
\text { contribui para o grupo de que maneira? }\end{array}$ \\
\hline & $\begin{array}{l}\text { 17. Quais os pontos fortes e fracos do DU? Para terminar, há algo que você } \\
\text { gostaria de falar que eu não tenha perguntado? }\end{array}$ \\
\hline
\end{tabular}

Revista de Direito da Cidade, vol. 10, no 2. ISSN 2317-7721 pp. 662-689 


\section{ANEXO B}

\begin{tabular}{|c|c|c|c|c|c|c|c|c|}
\hline \multicolumn{3}{|c|}{$\begin{array}{l}\text { Data: } \\
N^{\circ} \text { total de posts: }\end{array}$} & \multicolumn{5}{|c|}{$\begin{array}{l}\text { Acompanhamento das postagens da página do DU no Facebook } \\
\text { Dinâmica das cinco postagens com maior número de curtidas }\end{array}$} & \multirow[b]{2}{*}{$\begin{array}{c}\text { Hora } \\
\text { do } \\
\text { post }\end{array}$} \\
\hline & $\begin{array}{l}\text { Assunto } \\
\text { específico }\end{array}$ & $\begin{array}{l}\text { Tema } \\
\text { geral }\end{array}$ & $\begin{array}{l}\mathrm{N}^{\circ} \text { de } \\
\text { curtidas }\end{array}$ & $\begin{array}{l}\mathrm{N}^{\circ} \text { de } \\
\text { comentários }\end{array}$ & $\begin{array}{c}\text { A pessoa que } \\
\text { mais } \\
\text { comentou } \\
\text { (quando houve } \\
\text { apenas um que } \\
\text { comentou } \\
\text { mais vezes) }\end{array}$ & $\begin{array}{l}\text { O comentário } \\
\text { mais curtido } \\
\text { (quando houve } \\
\text { apenas um } \\
\text { comentário } \\
\text { mais curtido) }\end{array}$ & $\begin{array}{c}\text { Autor } \\
\text { do } \\
\text { post }\end{array}$ & \\
\hline 1. & & & & & & & & \\
\hline 2. & & & & & & & & \\
\hline 3. & & & & & & & & \\
\hline 4. & & & & & & & & \\
\hline 5. & & & & & & & & \\
\hline
\end{tabular}

Trabalho enviado em 19 de setembro de 2017.

Aceito em 13 de fevereiro de 2018.

\footnotetext{
$\left.{ }^{21} 1\right)$ Postagens de cunho informativo sobre acontecimentos gerais em qualquer lugar do mundo, 2) Denúncias e queixas de irregularidades ocorridas em Pernambuco, 3) Outras (especificar).
} 